\title{
The smart grid concept applied to an industrial electrical system
}

\author{
Isidro Fraga Hurtado ${ }^{1}$, Julio Rafael Gómez Sarduy ${ }^{2}$, Percy Rafael Viego Felipe ${ }^{3}$, Vladimir Sousa \\ Santos $^{4}$, Enrique Ciro Quispe Oqueña ${ }^{5}$ \\ ${ }^{1}$ Refinería de Cienfuegos, Cienfuegos, Cuba \\ ${ }^{2,3}$ Center of Energy and Environmental Studie, Universidad de Cienfuegos, Cienfuegos, Cuba \\ ${ }^{4}$ Energy Department, Universidad de la Costa, Barranquilla, Colombia \\ ${ }^{5}$ Energy and Mechanical Department, Universidad Autónoma de Occidente, Cali, Colombia
}

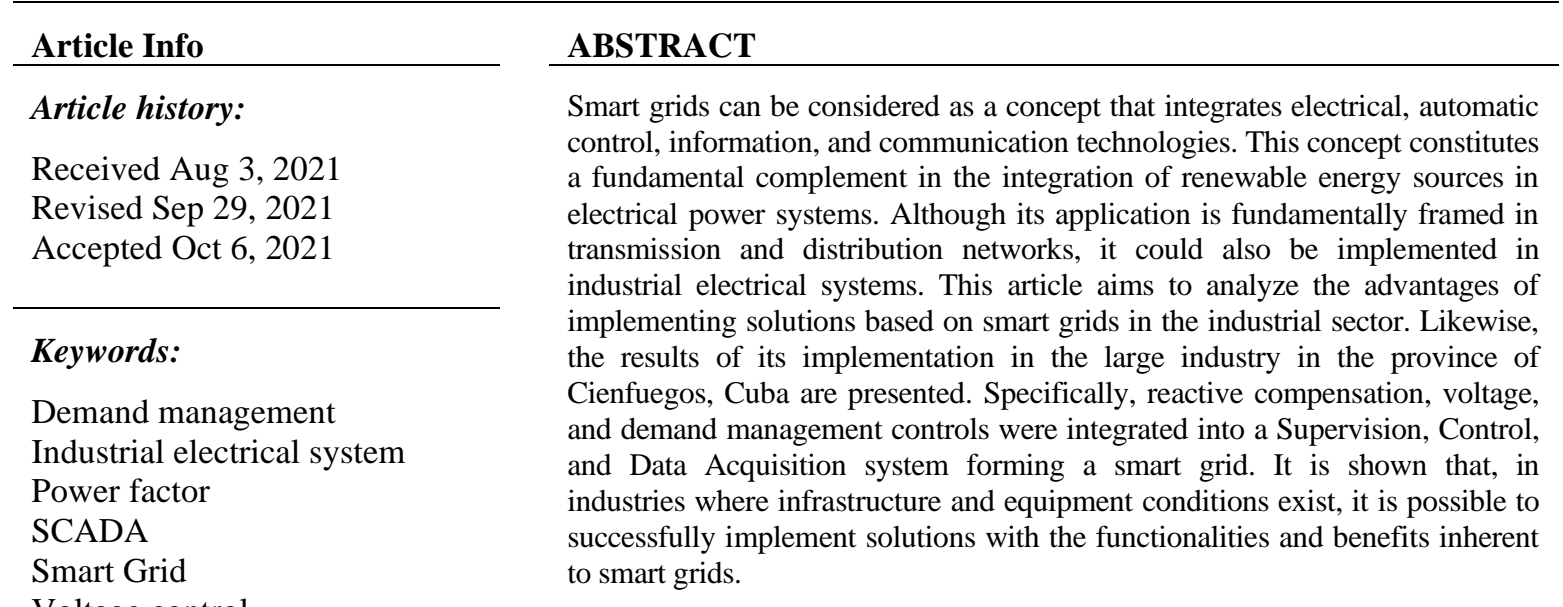

Voltage control

\section{Corresponding Author:}

Vladimir Sousa Santos

Energy Department

Universidad de la Costa

Calle 58 No.55-66, Barranquilla, Colombia

Email: vsousa1@cuc.edu.co
This is an open access article under the CC BY-SA license.

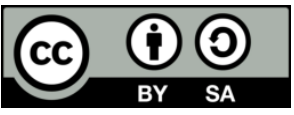

\section{INTRODUCTION}

The depletion of fossil fuels and climate change is a reality that is developing environmental awareness in the world on how to reduce the sources of generation of greenhouse gases. Many countries have already set targets for energy production low in $\mathrm{CO}_{2}$ emissions, investing in efficiency and renewable energy sources. The business and public sector want to reduce the costs of its products and services, and the residential sector wants to reduce the amount of its electricity bill. These realities impose a new way of managing energy resources [1], [2]. In the electricity sector, the implementation of various technologies included within the smart electric grids (SEG) concept contributes to achieving these purposes, since their implementation implies the application of advanced communication and control technologies and practices that improve reliability, efficiency, and security. The definition of SEG varies depending on the scope of each actor (i.e. institution, electricity company, technology manufacturer, or client) since each one has a different perspective of the same reality depending on their interests [3].

An SEG can be defined as a scheme that combines various technologies that allow to automatically monitor, protect, and optimize the operation of all interconnected elements. SEGs can be applied in 
centralized and distributed generation, transmission, and distribution systems, in industrial and commercial users and buildings, and can be integrated into energy storage systems, electric vehicles, thermostats, and other accessories and consumer devices. This list is very extensive and is constantly evolving, as some technologies are considered mature, and others are under development [4]-[8].

Recent advancements in information and communications technology concepts embedded in industries have enabled the emergence of Industry 4.0. The key to this new industrial revolution is to make factories smart enough to identify flaws or inefficiencies in the production process and react in a very short time to act and correct these flaws. In Industry 4.0, SEGs can play a dominant role in strengthening the overall flexibility of manufacturing resources, including power systems, to increase productivity [9], [10].

The different actors of the electricity system, depending on their scope, expect economic, socioproductive, and environmental benefits from the implementation of SEGs. Some of these benefits include the postponement of investments to increase the generation capacity, the optimization of the operation of the power plants, and the reduction of costs for maintenance and operation, measurements, technical and nontechnical losses, and cost of energy [6]. Besides, it seeks to reduce sustained and momentary power outages and service restoration costs. All of this can have a positive impact on the reduction of $\mathrm{CO}_{2}$ emissions in the generation and transmission of electricity [5].

Most of the benefits of an SEG are desirable in an industrial power grid since in these systems electricity must be reliably available for the production process. Currently, the electrical networks of industries have incorporated many elements of SEGs such as Supervision, control, and data acquisition systems (SCADA), centralized and decentralized power factor compensation systems, voltage compensation systems under load in transformers, distributed generation, harmonic filter, among others. These elements, however, are operating in isolation without integration [8], [11].

Based on this, recent research has highlighted the advantages of integrating SEGs into industrial electrical systems [6]. Some research works focus on solutions such as demand response (DR) systems [6], [8], [12]-[17], energy storage [18], reactive compensation [19], power quality control [20]-[22], [23] load control [24], [25], and communication technologies [26], [9], [27]. In Cuba, where the industry object of this study is located, the feasibility of implementing components that can integrate an SEG has been studied. In [28] a model composed of a network of multi-hop wireless sensors for low-cost and wide-area home automation systems is evaluated. J. Nuñez et al. [29] a tool is proposed for the implementation of a SCADA system for desalination processes.

Mendoza et al. [30] the development and implementation of an architecture for intelligent sensors applied to the filtering operation of a water treatment plant are evaluated. While [31] and [32] present a flexible communications supervisor model and a fault diagnosis methodology applied to photovoltaic systems respectively. Samad et al. [6] that the industrial sector has traditionally been involved in managing the use of electrical energy with technologies that are not part of the SEGs. In this study, they developed a review to motivate the use of SEG applications in industries. The authors describe the characteristics of the technologies used in SEGs and automated DR programs, based on case studies applied in aluminum processing plants, cement factories, food processing plants, and industrial cooling facilities.

The work discusses aspects that should be added to the operating standards, the advances in automated DR programs, the optimization of energy use, and the most dynamic markets that allow the boost in the use of SEGs. An important conclusion of this work is that industrial facilities, due to their large energy footprint, must be key players in the application of SEGs. In the authors' opinion, the industrial sector has not sufficiently understood the great advantages of the application of SEGs, which is evidenced in the little participation of this sector in the development of standards and research activities related to the SEGs.

ABB [8] a clearer vision of the SEG concept in the industry is given. This technical report concludes that to improve utilization, reliability, and availability in an ideal future distribution network, new initiatives such as more efficient motors and transformers are needed, as well as the application of the SEG concept. The authors show how the first version of an industrial smart grid was developed by ABB in the pulp and paper industry. In the industrial user environment, the level of intelligence of the existing technology in aging industries and the interest in new investments to increase the functionality and energy efficiency of the distribution network, are the aspects that define the program for an expansion towards the SEG within the pulp and paper industry. The cost of energy as a raw material is increasing and therefore an SEG is considered a feasible solution in the future [8].

Several works related to industrial SEG focus on the implementation of DR measures [6], [8], [12][17]. Generally, there are certain peak hours when demand is higher, and more power needs to be generated. DR algorithms allow the grid to make smart decisions during peak hours to reduce power consumption without affecting productivity. To implement a DR strategy in the industries, the electricity supply company monitors electricity consumption to assess demand and provides the industrial customer with price 
information in real-time. With this information, the industrial customer can program certain electrical loads to reduce their energy costs and make the demand better adapt to the supply.

Alam et al. [15] a demonstration system based on DR in an industrial SEG using wireless technologies is described. This study looks at the benefits of this technology compared to conventional wired networks by improving flexibility and reducing installation and maintenance costs. Xenos et al. [13] the concept of industrial smart grids is discussed as an extension of the SEG concept that includes large industrial consumers. The DR strategy is also recognized as an integral element of an SEG. This study assesses the potential of a large chemical plant to support the electrical grid through DR programs and proposes methods to assess the flexibility of the plant to provide reserves of electrical energy without affecting production.

Zhou et al. [18] an energy management system for industry based on energy storage is presented under the SEG concept, applied in the Shenhua coal mine, in China. The system uses a solution based on Energy 3 technology developed by NICE (national institute for clean and low carbon energy) and four typical functions were analyzed using a digital simulation. This work is the first application of SEG technology in the coal mining industry. The proposed system expands SEG research and development across large industries, contributing to policy development for the power grids of the future.

Achieving efficient and economical performance of the electrical supply system is one of the functions of an industrial SEG. Reactive compensation is one of the most effective ways to reduce the cost of electrical energy consumed, improve power quality, reduce losses, and increase energy efficiency. Several studies propose strategies aimed at improving the power factor in all nodes of an industrial electrical system using efficient drives [33].

Maklakov et al. [19], a theoretical study is carried out to define the perspectives of integration of electric drives based on "back to back" converters in an industrial SEG. These converters can be used in the operation of the company's power supply system as they can provide controlled power factors and bidirectional power flow. The study proposes the principle of maximum use of the consumption current in the converter to improve efficiency, recommending its installation in parallel with a non-linear load.

The adoption of an SEG in an industry depends on its technological availability. This was demonstrated in a study conducted in 2015, in four Danish companies as case studies [34]. In this study, we present the factors that influence the adoption of an SEG (that is, acceptance and continued participation) by industrial consumers, as well as the key activities that can affect the adoption process. The results of the study showed that the adoption of SEG is determined by technological availability and the change in consumer behavior.

Among the investigations reported, those associated with technologies that make up the infrastructure of industrial SEGs and that play an important role, such as communications, are related. Spectrum selection techniques needed to take advantage of SEG requirements and allow industrial users to transfer data using licensed or free bands are investigated in [12]. The "backbone" of SEG is information and communication technologies (ICT). Electric grids are considered smart if they have coordinated control, distributed automation, and monitoring systems. It must also have interaction of the control system with the operating devices, as well as there must be communication between measured data and decision-making devices. The operator can have tools that operate automatically or give operating instructions in different cases [26], [9].

There are tools for power quality control, such as automatic load shedding, transformer on-load tap changer control, filter bank control, generator excitation control, and reactive energy control, among others. The prediction of slow-growing failures can also be included in an SEG. An example is the identification of the decrease in the operating capacity of a motor by detecting an increase in the trend of its operating temperature [35].

Monitoring the load factor of the network and individual equipment is necessary for optimal control of energy flow [25]. Besides, the breaking and operating current values of the switches provide valuable information for planning maintenance services. This data is obtained through sensors and measuring devices, or by intelligent devices such as protection relays, process controllers, intelligent motors, etc., which use the measured local information and are connected to an information field bus. Motivated by the proposal of Samad and Kiliccote [6] to continue promoting the application of the concept of SEGs within the industrial sector and the need to improve energy management in large consumers in Cuba, the present investigation is proposed. Although these are important steps in the direction of improving management processes in the generation and consumption of energy in Cuba using automation elements, there is still no evidence of the development of models that integrate these components and others mentioned that allow the development and implementation of SEGs in the Cuban industrial sector.

This article aims to analyze the advantages of implementing solutions based on SEGs in the industrial sector. Also, the results of the implementation of this type of solution in large industries in the 
province of Cienfuegos, Cuba are presented. Specifically, the implementation of the following three integrated control schemes was evaluated: reactive compensation, voltage control, and demand management. The contribution of this work consists of the evaluation for the first time of this type of solution in the context of the Cuban industrial sector.

\section{RESEARCH METHOD}

\subsection{Materials and methods}

The following describes the electrical system of the industry under study and the reactive compensation, voltage control, and demand management schemes that make up the proposed SEG. The industry presents the electrical supply scheme shown in Figure 1. This circuit is of the radial type, medium voltage with the selective secondary distribution. The electrical system has a main substation fed by two 110 $\mathrm{kV}$ lines. It also has two $25 \mathrm{MVA}$ power transformers and three windings with voltages of 110/6.3/6.3 kV that feed four bars at $6.3 \mathrm{kV}$ through the secondary. The transformers work with an automatic on-load tapchanger on the high voltage side and have a SCADA system implemented.

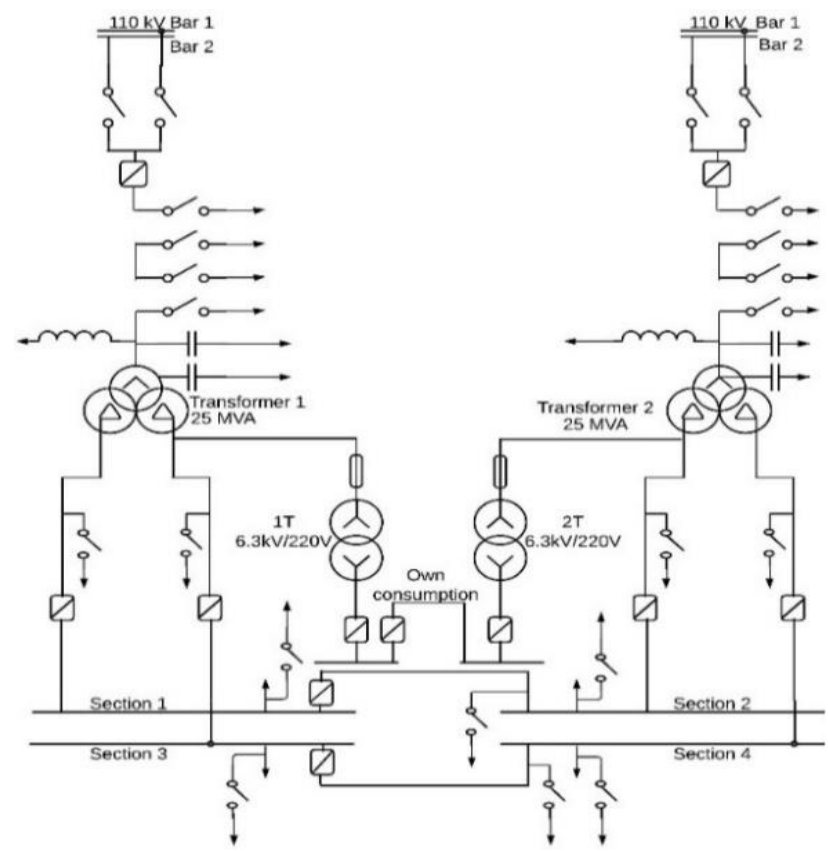

Figure 1. General one-line diagram of the industry

\subsubsection{Power factor management system design}

In industry, reactive compensation is carried out from the transformer using synchronous motors placed in medium voltage and automatic capacitor banks placed in low voltage substations. In synchronous motors, the power factor can be adjusted manually, taking as reference the motor itself or the substation bus to which it is connected.

Capacitor banks have three steps that are automatically connected and disconnected depending on the desired power factor in the substation bus to which they are connected. Synchronous motors compensate for some medium voltage substations on two bars, while capacitor banks compensate for half of the low voltage substations on the four bars. The changes implemented for the management of the power factor were carried out through communication between the protection, control, and measurement equipment installed in medium voltage and the SCADA system. The steps for the implementation of the power factor management system and the equipment that supports it is shown in Figure 2.

Power consumption measurements are made at the input of each bus and monthly power factor calculations are run from the SCADA system. This management system uses the capacitor banks installed in the low voltage substations to provide reactive to the medium voltage network and thus reduce the reactive consumption of the national electroenergy system (NES), increasing the power factor. The SCADA system has in the Automation branch the Calculation Editor sub-branch with 54 predefined functions. Function 53 is selected which calculates the maximum, minimum, and average of an analog variable monthly and saves the 
values in the variables that are designated. Considering that energy consumption is a continuously increasing cumulative variable, the monthly minimum and maximum values are recorded, and with these values, the calculation of the power factor is programmed. Depending on the value obtained, the telecommands are sent to connect or disconnect the steps of the capacitor bank.

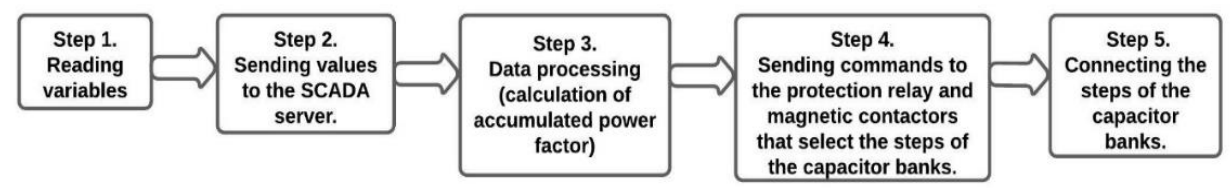

Figure 2. Steps for the implementation of the power factor management system

\subsubsection{Voltage control system design}

Voltage control in the main substation is carried out by two automatically operated on-load tapexchangers. The exchangers have the limitation that they only receive voltage signals from one of the two bars of each transformer. The steps for the implementation of the voltage control system and the equipment that supports it are shown in Figure 3.

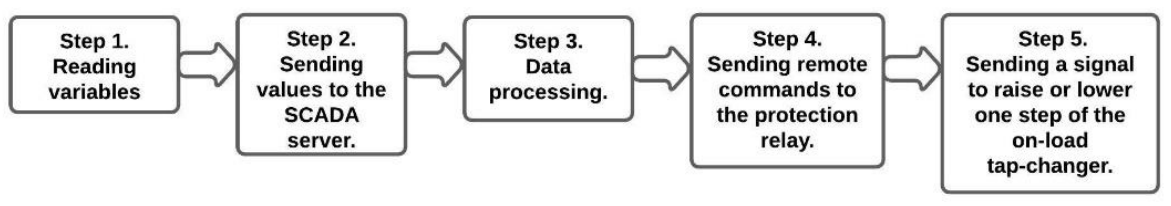

Figure 3. Steps for the implementation of the voltage control system

To process the data stored within the automation branch of the SCADA SERVER program, a script is created that compares the phase voltage values of bus two and bus four stored in the server with a maximum predefined value; and if it exceeds it for a certain time, a telecommand is sent to the bus input relay four, so that it issues an order to the on-load tap-changer to raise the shunt one step and thus lower the voltage. If the voltage is less than the predefined value, the remote control is sent to the same relay to issue an order to the on-load tap-changer to lower the bypass one step and thus raise the voltage. The waiting time of the telecommands is calculated from a linear regression model that relates the minimum and maximum voltages and the response time. Figure 4 (a) shows the model for the low voltage side and Figure 4 (b) for the high voltage side.

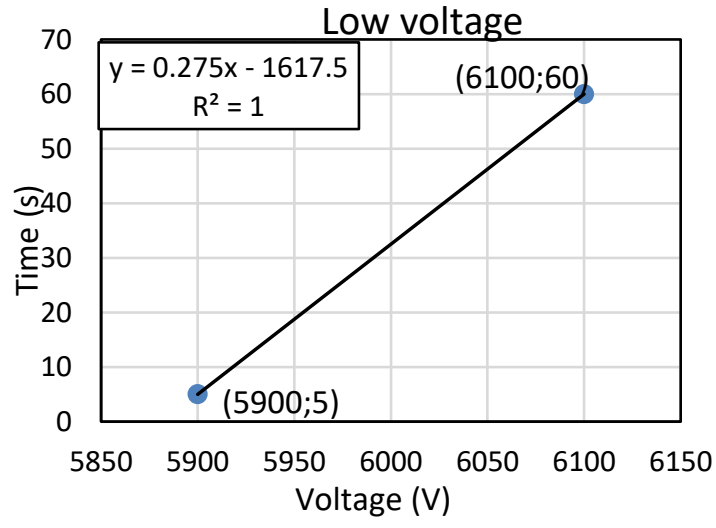

(a)

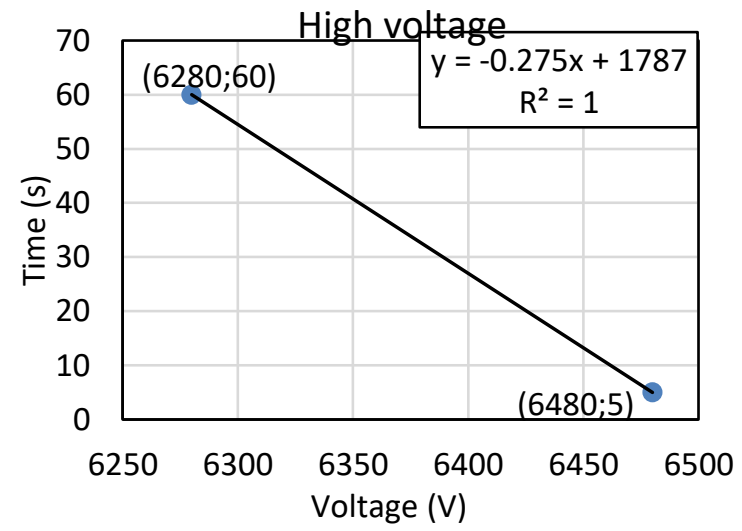

(b)

Figure 4. Waiting time to send telecommands: (a) low voltage and (b) high voltage 


\subsubsection{Demand management system design}

In Cuba, one of the contracting parameters for the energy service between the electricity company and the industries is the payment for maximum demand at peak-peak hours (5:00 pm to 5:30 pm) established by the national office for the control and rational use of energy (ONURE). This is a fixed amount that the company must pay for claims equal to or less than the contracted value and if this value is exceeded, the industry must pay a surcharge.

Electrical energy measurements in the industry are carried out in the main substation, while connection and disconnection operations of electrical loads are carried out in the operations office. These locations are distant and communication between them is carried out by telephone or by trunking radio systems during peak-peak hours. The dispatch operators receive the information on the electricity demand offered by the substation operators and take the necessary actions to avoid exceeding the maximum contracted demand value. This communication is often not effective as it is not done in real-time and sometimes the reported demand differs from the actual demand.

The steps for the implementation of the Demand Management System begin by monitoring the electrical variables in real-time with the ION7650 [36] intelligent electrical devices. This data is displayed in real-time in the distributed control system (DCS) so that process plant operators can actively manage their demand as shown in Figure 5 (a). The data is also presented on the company's website to be a source of information for plant technologists, plant managers, plant supervisors, electrical technical services technicians, and managers in general as shown in Figure 5 (b). On the DCS screen, the option to enter the maximum demand alarm value is enabled and the Business website shows the values.

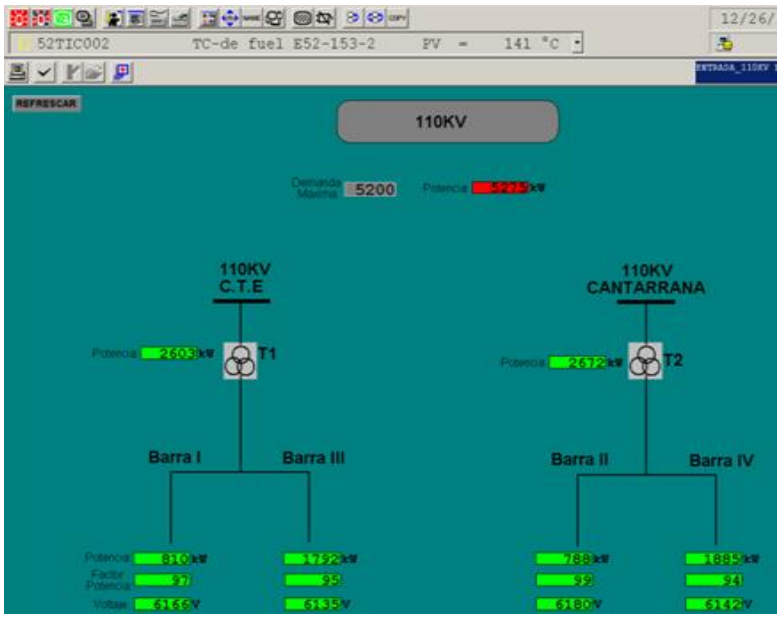

(a)

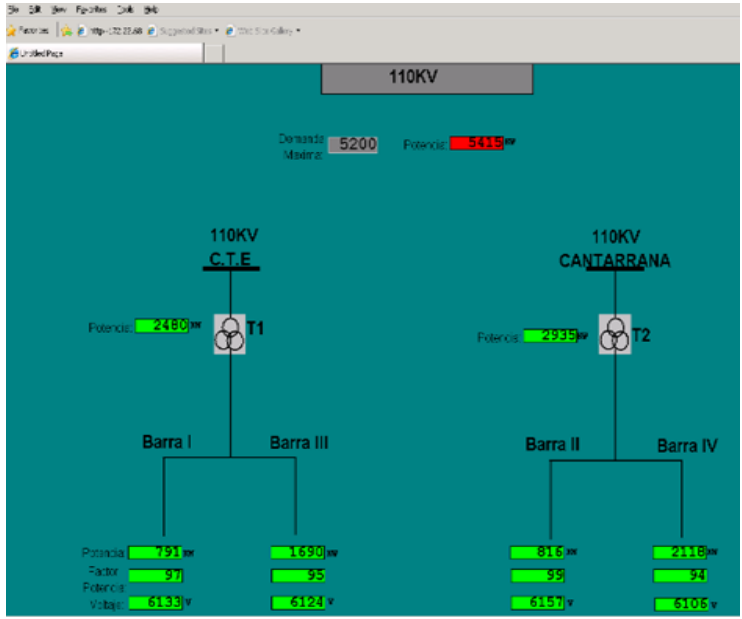

(b)

Figure 5. These figures are; (a) DCS screen, (b) company's website

In Figure 5 (a) it can be seen in the upper left corner that the visual and audible alarm is activated since the maximum demand value was exceeded. In this situation, the operators begin to disconnect the nonessential loads until the demand value is lower than the maximum demand. This data is also monitored on the company's website as can be seen in Figure 5 (b).

\subsubsection{Measurement and protection equipment}

Two types of measurement and protection technologies coexist in the medium-voltage network. On the one hand, there is the digital measurement and protection equipment integrated into the SCADA project, and on the other, in the substations without modernization, analog measurement equipment and electromechanical protection are used.

In the SCADA project, the IEC 61850 [37] communications protocol was used between the relays, substations, and servers. In medium voltage, during the substation modernization process, the original switches, blades, and current and voltage transformers were maintained. All electromechanical protection relays were replaced by digital relays and the data exchange between the relays and the final equipment was maintained with the wiring. 
The modernization of the medium voltage network is linked to the development of the SCADA project, which is currently used for the monitoring of field devices, remote control, and local switches. With the SCADA system, the operator station receives the readings and display of parameters, as well as the records of alarms and operations. In technical services, the issuance of reports is received by e-mail. Despite the technical availability of the SCADA system, it does not have implemented programs or functions using the automation branch. The information exchange branch is also not used to exchange data with other systems.

\subsubsection{The technological basis for the implementation of the SEG concept in the industry}

The electrical power system network of the industry under study has implemented technologies with processing capacity with a certain level of local automation. However, these technologies are not integrated in terms of operation, as each processes its data independently and is only communicated for data monitoring functions

These technologies are:

- Survalent Electrical SCADA.

- Automatic local control system for capacitor banks.

- A voltage control system in the on-load tap-changers of the two main transformers.

The implementation of the SEG concept starts from the integration into the SCADA system of the following operations that are currently performed manually:

- Global reactive power control.

- Voltage control in on-load tap-exchangers.

- Demand management.

The SCADA Survalent system has an automation branch with the option of scripting programming. This allows you to define and run programs that use database points for control sequence calculations. With the function editor, historical and calculated values can be stored for use in control sequence calculations. Furthermore, you can use an OPC server that can be used for the exchange of information with the distributed control system (DCS).

\section{RESULTS AND DISCUSSIONS}

The SEG made up of the power factor management system, voltage control system, and demand management system was implemented at the end of 2017 and began operating in 2018. Figure 6 shows a diagram of the designed and implemented system.

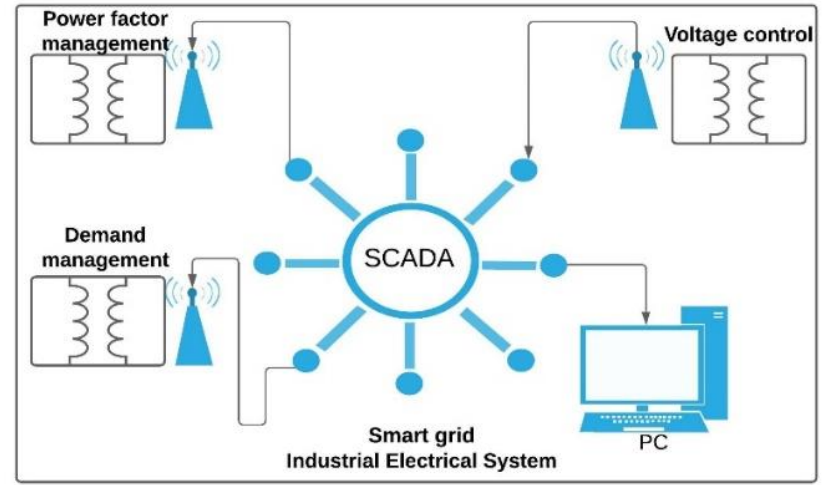

Figure 6. Diagram of the SEG developed

\subsection{Power factor management system}

Before the implementation of the SEG system, reactive compensation was deficient since they did not achieve a positive balance between bonuses and penalties for the concept of power factor in the electricity bill. The penalty costs reached \$ US 33,136.28 in 2016 and \$ US 49,305.45 CUC in 2017. After implementing the SEG system, the results achieved were satisfactory since no penalties were received and the bonuses for the power factor in the electricity bill reached the value of 160,395.52 CUC in the period from January to July 2018.

\subsubsection{Voltage control system}

Int J Pow Elec \& Dri Syst, Vol. 12, No. 4, December 2021 : 2140 - 2150 
Regarding the voltage control, before the implementation of the SEG system, there was no adequate control as the measured signals were insufficient. Due to this and the variable behavior of voltage variations, there were days in which operations were not executed, while on other days dozens of operations were presented in the voltage exchangers. After the SEG system is implemented, the voltage regulation in the industrial is improved. Figure 7 shows a graph of the voltage measurements in a period after the implementation of the system.

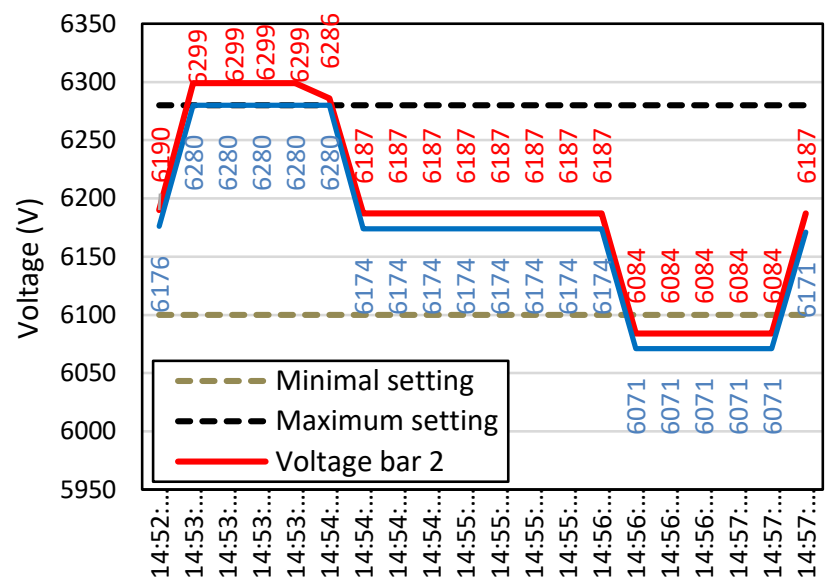

Figure 7. Report of voltage measurements

In this figure, four vertical bars (A-B, and $\mathrm{C}-\mathrm{D}$ ) indicate the time intervals in which voltage deviations occurred outside of the maximum and minimum limits set for system voltage regulation. The figure also shows the restoration of the voltage within the specified limits because of the SEG response.

\subsubsection{Demand management system}

Concerning the maximum demand contracted with the electricity company, the way it was managed before the implementation of the SEG system was inefficient. As evidenced in Figure 8 (a), this caused this value to be exceeded on many occasions with the consequent overpayments due to penalties. With the implementation of the SEG system, it was possible to control the maximum demand of the system, keeping it below the contracted value without affecting production. Figure 8 (b) shows a graph with the demand values for the two days after the implementation of the solution. As can be seen in the figure, the demand remained below the limit established by ONURE, demonstrating the effectiveness of the system in controlling demand.

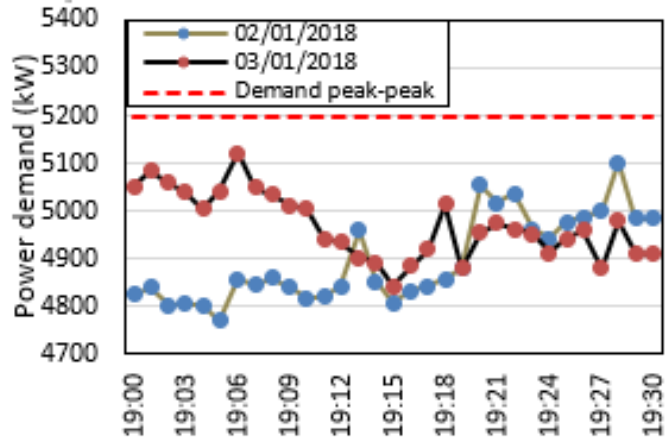

(a)

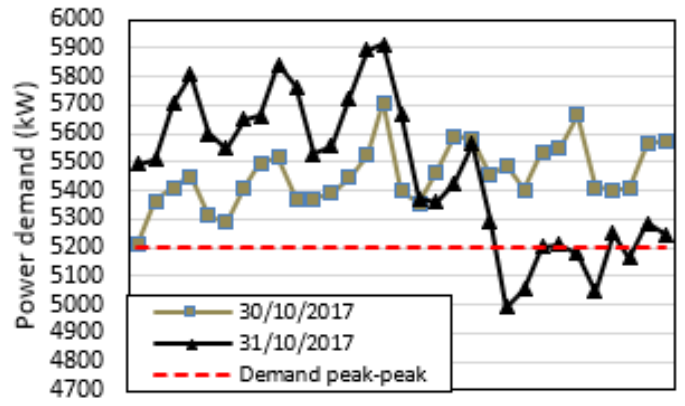

8 중 ओं

(b)

Figure 8. (a) behavior of the maximum demand, (b) graph with demand values of the peak-peak hours after the solution are implemented 


\section{CONCLUSION}

The literature consulted shows that the concept of SEG has been mostly dealt with for power systems and not for industries. In many industries, power supply systems have a high degree of intelligence and functionality including SCADA systems, which constitute a starting point for the implementation of the SEG concept. In this work, the implementation of an SEG system in an industry understudy was presented, which has an electrical SCADA, as well as measurement and protection equipment facilities. The SEG system made it possible to optimize peak-peak demand management, global reactive power compensation, and control of voltage variation.

With the implementation of the SEG system, reactive compensation was achieved, with net billing balances of 160,395.52 CUC in 6 months for this concept. The voltage control was adequately guaranteed with the use of protection relays and the SCADA system, avoiding investing in dedicated equipment. Likewise, with the implementation of the SEG, demand management is carried out more functionally, fulfilling the objective of keeping the maximum demand below the contracted demand during peak hours. This research shows that in those industries where there is some infrastructure conditions and measurement and control equipment, it is possible to implement solutions with functionalities and features typical of an SEG, which constitutes an open field for research.

\section{REFERENCES}

[1] J. J. C. Eras et al., "Energy management in the formation of light, starter, and ignition lead-acid batteries," Energy Efficiency, vol. 12, no. 5, pp. 1219-1236, 2019.

[2] J. R. Gómez, E. C. Quispe, R. del P. Castrillón, and P. R. Viego, "Identification of Technoeconomic Opportunities with the Use of Premium Efficiency Motors as Alternative for Developing Countries," Energies, vol. 13, no. 20, p. 5411, 2020, doi: 10.3390/en13205411.

[3] M. Zeng and B. N. Jørgensen, "Global Smart Grid Transmission: Comparison of Europe, the US, and China," Proceedings of The 10th International Green Energy Conference, 2015.

[4] H. J. Loschi et al., "Energy Efficiency in Smart Grid: A Prospective Study on Energy Management Systems," Smart Grid Reneweble Energy, 2015.

[5] M. Madrigal, R. Uluski, and K. Mensan Gaba, "Practical Guidance for Defining a Smart Grid Modernization Strategy: The Case of Distribution (Revised Edition)," Word Bank Publication, 2017.

[6] T. Samad and S. Kiliccote, "Smart grid technologies and applications for the industrial sector," Computers \& Chemical Engineering, vol. 47, pp. 76-84, 2012, doi: 10.1016/j.compchemeng.2012.07.006.

[7] S. Chakraborty, A. Chowdhury, and S. Chakraborty, "Smart Grids \& smart grid technologies in India," International Research Journal of Engineering and Technology, vol. 4, no. 1, pp. 1536-1541, 2017.

[8] ABB, "Industrial Smart Grid Smart Grid in Industrial Networks," SCRIBD, 2010.

[9] M. Faheem et al., "Smart grid communication and information technologies in the perspective of Industry 4.0: Opportunities and challenges," Computer Science Review IRJET, vol. 30, pp. 1-30, 2018, doi: 10.1016/j.cosrev.2018.08.001.

[10] M. A. Berawi et al., "Accelerating Sustainable Energy Development through Industry 4.0 Technologies," International Journal of Technology, vol. 11, no. 8, pp. 1463-1467, 2020, doi: 10.14716/ijtech.v11i8.4627.

[11] C. Martin, F. Starace, and J. P. Tricoire, "The Future of Electricity: New Technologies Transforming the Grid Edge," 2017.

[12] M. H. Shoreh, P. Siano, M. Shafie-khah, V. Loia, and J. P. S. Catalão, "A survey of industrial applications of Demand Response,” Electric Power Systems Research, vol. 141, pp. 31-49, 2016, doi: 10.1016/j.epsr.2016.07.008.

[13] D. P. Xenos, I. M. Noor, M. Matloubi, M. Cicciotti, T. Haugen, and N. F. Thornhill, "Demand-side management and optimal operation of industrial electricity consumers: An example of an energy-intensive chemical plant," Applied Energy, vol. 182, pp. 418-433, 2016, doi: 10.1016/j.apenergy.2016.08.084.

[14] S. Mitra, I. E. Grossmann, J. M. Pinto, and N. Arora, "Optimal production planning under time-sensitive electricity prices for continuous power-intensive processes," Computers \& Chemical Engineering, vol. 38, pp. 171-184, 2012, doi: 10.1016/j.compchemeng.2011.09.019.

[15] M. Alam, J. Kim, Y. Li, S. H. Hong, X. Li and A. Xu, "Implementation of wireless industrial networks for industrial smart grids," International Conference on Advances in Energy Conversion Technologies (ICAECT), 2014, pp. 83-87, doi: 10.1109/ICAECT.2014.6757066.

[16] S. Bahrami and A. Sheikhi, "From Demand Response in Smart Grid Toward Integrated Demand Response in Smart Energy Hub," IEEE Transactions on Smart Grid, vol. 7, no. 2, pp. 650-658, 2016, doi: 10.1109/TSG.2015.2464374.

[17] M. Yao, Z. Hu, N. Zhang, W. Duan and J. Zhang, "Low-carbon benefits analysis of energy-intensive industrial demand response resources for ancillary services," Journal of Modern Power Systems and Clean Energy, vol. 3, no. 1, pp. 131-138, 2015, doi: 10.1007/s40565-015-0102-6.

[18] G. Zhou, F. Wang, T. Wu, X. Zhao and S. Chen, "Energy storage based industrial power management system under smart grid concept," International Conference on Intelligent Green Building and Smart Grid (IGBSG), 2014, pp. 16, doi: 10.1109/IGBSG.2014.6835265. 
[19] A. S. Maklakov and A. A. Radionov, "Integration prospects of electric drives based on back to back converters in industrial smart grid," 12th International Conference on Actual Problems of Electronics Instrument Engineering (APEIE), 2014, pp. 770-774, doi: 10.1109/APEIE.2014.7040790.

[20] F. E. Hoyos Velasco, J. E. Candelo, and J. I. Silva Ortega, "Performance evaluation of a DC-AC inverter controlled with ZAD-FPIC," INGE CUC, vol. 14, no. 1, pp. 9-18, 2018.

[21] W. Choi, W. Lee, D. Han and B. Sarlioglu, "New Configuration of Multifunctional Grid-Connected Inverter to Improve Both Current-Based and Voltage-Based Power Quality," IEEE Transactions on Industry Applications, vol. 54, no. 6, pp. 6374-6382, 2018, doi: 10.1109/TIA.2018.2861737.

[22] L. Yunshuo, D. Jian, L. Jun, F. Min and Y. Qing, "Research on distribution power quality monitoring based on distribution internet of things," 14th IEEE International Conference on Electronic Measurement \& Instruments (ICEMI), 2019, pp. 1849-1854, doi: 10.1109/ICEMI46757.2019.9101884.

[23] S. D. Panjaitan, B. W. Sanjaya, and R. Kurnianto, "Fuzzy-IP Controller for Voltage Regulation in a Stand-Alone Microgrid System," International Review of Automatic Control, vol. 11, no. 3, pp. 143-150, 2018.

[24] D. Han and X. Li, "The Forecasting of Electrical Consumption Proportion of Different Industries in Substation Based on SCADA and the Daily Load Curve of Load Control System," International Conference on Computer Distributed Control and Intelligent Environmental Monitoring, 2012, pp. 738-741, doi: 10.1109/CDCIEM.2012.180.

[25] Cuimei Bo, Shi Zhang, Jinguo Lin, Cuimei Bo and Zhiquan Wang, "Design \& Application of the Automatic Load Control System of Butadiene Product Equipment," 6th World Congress on Intelligent Control and Automation, 2006, pp. 7720-7724, doi: 10.1109/WCICA.2006.1713470.

[26] M. Yu, M. Zhu, G. Chen, J. Li and Z. Zhou, "A cyber-physical architecture for industry 4.0-based power equipments detection system," International Conference on Condition Monitoring and Diagnosis (CMD), 2016, pp. 782-785, doi: 10.1109/CMD.2016.7757942.

[27] W. S. Ocaña, A. M. Abata, E. S. Jácome, and V. M. Mora, "Distributed systems and industrial communication networks with the internet of things, aimed at industry 4.0," International Review of Automatic Control, vol. 12, no. 5, pp.129, 2019, doi: 10.15866/ireaco.v12i5.17687.

[28] E. Mendoza, P. Fuentes, I. Benítez, D. Reina, and J. Núñez, "Red de sensores inalámbricos multisalto para sistemas domóticos de bajo costo y área extendida," RIAI - Revista Iberoamericana de Automática e Informática industrial : Revista Iberoamericana de Automática e Informática, vol. 17, no. 4, p. 412, 2020, doi: 10.4995/riai.2020.12301.

[29] J. Nuñez, I. F. Benítez Pina, A. Rodríguez Martínez, S. Díaz Pérez and D. Luiz de Oliveira, "Tools for the Implementation of a SCADA System in a Desalination Process," IEEE Latin America Transactions, vol. 17, no. 11, pp. 1858-1864, 2019, doi: 10.1109/TLA.2019.8986424.

[30] E. Mendoza, J. Andramuño, J. Núñez, and I. Benítez, "Deliberative architecture for smart sensors in the filtering operation of a water purification plant," Journal of Physics: Conference Series, vol. 1730, no. 1, p. 1-9, 2021, doi: 10.1088/1742-6596/1730/1/012088.

[31] J. R. N. Alvarez, I. F. B. Pina, and Y. L. Albuerne, "Communications in Flexible Supervisor for Laboratory Research in Renewable Energy," IOP Conference Series: Materials Science and Engineering, vol. 844, no. 1, p. 111, 2020, doi: 10.1088/1757-899X/844/1/012016.

[32] J. R. A. Núñez, I. F. P. Benítez, R. Y. Proenza, L. S. Vázquez, and D. M. Díaz, "Metodología de diagnóstico de fallos para sistemas fotovoltaicos de conexión a red," Revista Iberoamericana de Automática e Informática industrial, vol. 17, no. 1, p. 1-12, 2020, doi: 10.4995/riai.2017.7133.

[33] K. Mehmood, Z. Li, M. F. Tahir, and K. M. Cheema, "Fast excitation control strategy for typical magnetically controllable reactor for reactive power compensation," International Journal of Electrical Power \& Energy Systems, vol. 129, p. 106757, 2021, doi: 10.1016/j.ijepes.2020.106757.

[34] Z. Ma, B. N. JØrgensen and A. Asmussen, "Industrial consumers' acceptance to the smart grid solutions: Case studies from Denmark," IEEE Innovative Smart Grid Technologies - Asia (ISGT ASIA), 2015, pp. 1-6, doi: 10.1109/ISGT-Asia.2015.7386994.

[35] T. Sun, R. Yang, H. Li, X. Zhang and T. Xu, "Active Motor Rotor Temperature Management Based on One-Node Thermal Network Model Predictive Control," IEEE Transactions on Power Electronics, vol. 35, no. 10, pp. 1121311221, 2020, doi: 10.1109/TPEL.2020.2979824.

[36] Schneider Electric, "PowerLogic ION7550 / ION7650 User Guide," 2019

[37] IEC, "IEC 61850-4:2011. Communication networks and systems for power utility automation - Part 4: System and project management," International Standard, 2011. 


\section{BIOGRAPHIES OF AUTHORS}
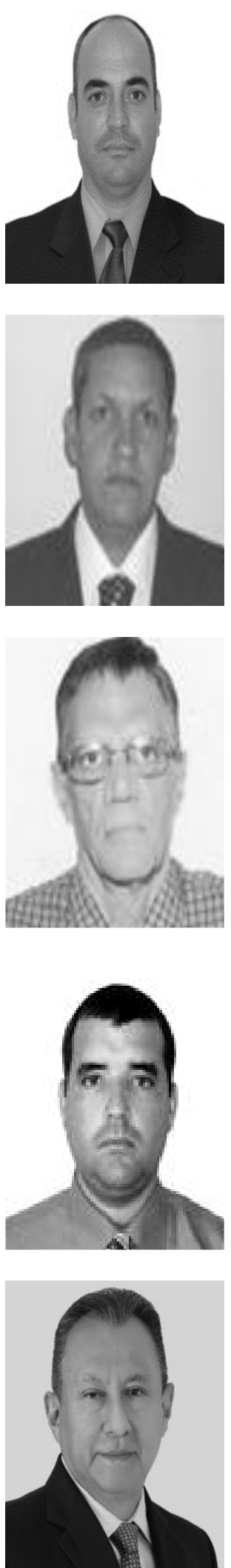

Isidro Fraga Hurtado was born in Cienfuegos, Cuba, in 1974. Received the B.S degree in electrical engineering from Universidad of Camaguey, Camaguey, Cuba, in 2001. Received the M.Sc. degree in electrical engineering from Universidad Central de Las Villas, Santa Clara, Cuba, in 2019. His area of interest includes smart grid power quality and energy efficiency in industrial power systems. Email: isidro.fraga@ nauta.cu.

Julio R. Gómez Sarduy was born in Cienfuegos, Cuba, in 1956. Received a B.S degree in electrical engineering from Universidad Central de Las Villas, Santa Clara, Cuba, in 1986. Received an M.Sc. degree in electrical engineering from Universidad Central de Las Villas, Santa Clara, Cuba, in 1996, from where he received his Ph.D. degree in 2006. He has published articles on induction motors, energy quality, and energy efficiency in high impact journals indexed in Scopus and Wos. His area of interest includes electric machines, power quality, and energy efficiency in industrial power systems. Email: jgomez@ucf.edu.cu, ID Scopus: 46461816400, ID ORCID: 0000-0003-3313-6572, ID Google Scholar: Julio Rafael Gómez Sarduy.

Percy R. Viego Felipe was born in Cienfuegos, Cuba, on November 19, 1944. Received a B.S. degree in Electrical Engineering from the Universidad Central de Las Villas, Santa Clara, Cuba, in 1965. Received the Dr.C. (Ph.D.) degree from the Universidad Central de Las Villas, Santa Clara, Cuba. He has published articles on induction motors, energy quality, and energy efficiency in high impact journals indexed in Scopus and Wos. His current research interests include the analysis of electrical machines and drives, power quality and management, and energy efficiency. Email: pviego@ucf.edu.cu, ID Scopus: 8594553000, ID ORCID: 00000002-6396-5737, ID Google Scholar: Percy Rafael Viego Felipe.

Vladimir Sousa Santos was born in Cienfuegos, Cuba, on November 21, 1980. Received a B.Sc. in Electrical Engineering from the Universidad Central de Las Villas, Cuba in 2004. M.Sc. in Energy Efficiency from Universidad Cienfuegos, Cuba in 2004. PhD. in Electrical Engineering from Universidad Central de Las Villas, Cuba, in 2014. He has published articles on induction motors, energy quality, and energy efficiency in high impact journals indexed in Scopus and Wos. His area of interest includes electric machines, power quality, and energy efficiency. Email: vsousa1 @ cuc.edu.co, ID Scopus: 57219326150, ID ORCID: 0000-00018808-1914, ID Google Scholar: Vladimir Sousa Santos, ID Publons: T-8233-2019.

Enrique C. Quispe Oqueña was born in Lima, Perú, on January 20, 1956. He received the B.Sc. in Electrical Engineering from the Universidad Nacional de Ingeniería, Perú in 1980. M.Sc. in Electrical Engineering, M. Eng. in Industrial Automation and PhD. in Electrical Engineering from Universidad del Valle, Colombia in 1994, 1997 and 2011, respectively. Since 1992, he has been with Universidad Autónoma de Occidente, Cali, Colombia, where he is currently Full Professor in the Department of Energy and Mechanics and the Director of the Energy Research Group. His current research interests include the analysis of electrical machines and drives, power quality and management and energy efficiency. He is an IEEE Senior Member. Email: ecquispe@uao.edu.co, ID Scopus: 13807518400, ID ORCID: 00000003-3223-1834, ID Google Scholar: Enrique C. Quispe Oqueña. 